\section{Notice of EGM}

Enclosed with this edition of the $B D J$ is notice of an Extraordinary General Meeting (EGM) of the Association, scheduled for 18 June 2005. The EGM is to consider amendments to the Articles of Association, the principle changes being the establishment of a Finance Committee and an Audit Committee.

The Finance Committee, a sub-committee of the Executive Board, will have a greater role in the scrutiny of financial matters than the current Remuneration Committee, which it replaces. An interim Finance Committee has been in operation since May last year and overseen the Association's recent financial recovery. These proposals will establish the Finance Committee as a permanent part of the Association's structure.

The BDA Representative Body has also recommended the establishment of an Audit Committee under its charge, which will monitor the governance and finances of all areas of the Association. The Audit Committee will have greater authority and access to information than the current Financial Review Group, which it will replace.

Three further changes are proposed. The first is to document a procedure for handling by-elections to the Executive Board, a subject on which the Articles of Association are currently silent.

The second proposal arises from legal advice, and is to amend the company director status of the Representative Body Chair. Whilst this proposal will not in practice affect the role of the Representative Body Chair, it will remove that office holder's legal status as a company director. The Articles of Association will stipulate that that the Representative Body Chair shall maintain the right of attendance and audience at all Executive Board meetings. Lastly, all reference to 'Chairman' would be replaced with 'Chair'.

\section{Dentist takes lead City role}

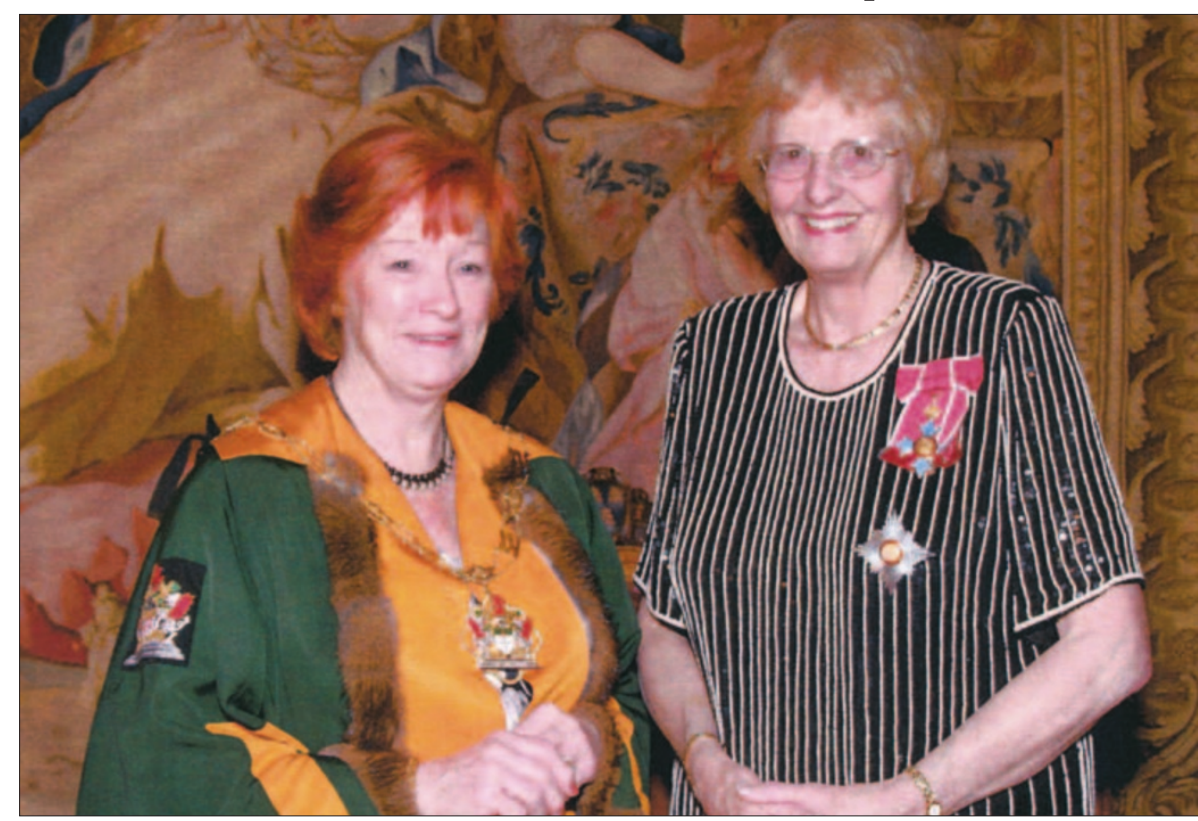

Mrs Ann Underwood has become the first dentist to be appointed Master of the Worshipful Company of Arbitrators. It is one of many Livery Companies which generally represent leading professions associated with the City of London and maintains a programme of activities which promote arbitration. Mrs Underwood qualified as a Bachelor of Dental Surgery in 1959 and as a Licentiate of the Royal College of Surgeons of England in the same year. She has been in general dental practice ever since and sits as a Chairman in the Adult and Family courts. She qualified as an Associate of the Chartered Institute of Arbitrators in 1989 and was appointed to Fellowship in 1995. Pictured above, Mrs Ann Underwood (left) with Dame Margaret Seward at the Company's annual Livery Banquet.

\section{Scottish dentist new President of BDA}

Falkirk dentist John Craig (pictured) was installed as the 118th President of the British Dental Association (BDA) at the 2005 British Dental Conference and Exhibition earlier this month.

He will serve a 12-month term of office during which he will represent the BDA across the UK and abroad. Since qualifying from Glasgow Dental School in 1966, Dr Craig has enjoyed a distinguished career in the profession and has been the senior partner of a Falkirk dental practice for over 30 years.

As well as serving as a family dentist in his native Scotland, he has been an eminent figure in postgraduate dental education and was instrumental in laying the foundations of the Faculty of General Dental Practitioners in Scotland.

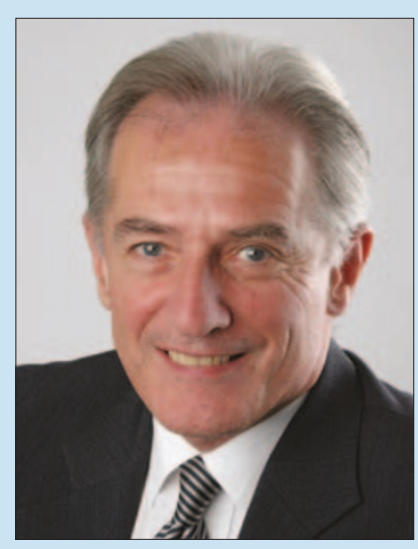

He was elected to the BDA's Representative Board in 1991 and was a member of the Executive Board for nine years, including three as deputy chairman. 


\section{Dentistry workforce could suffer says study}

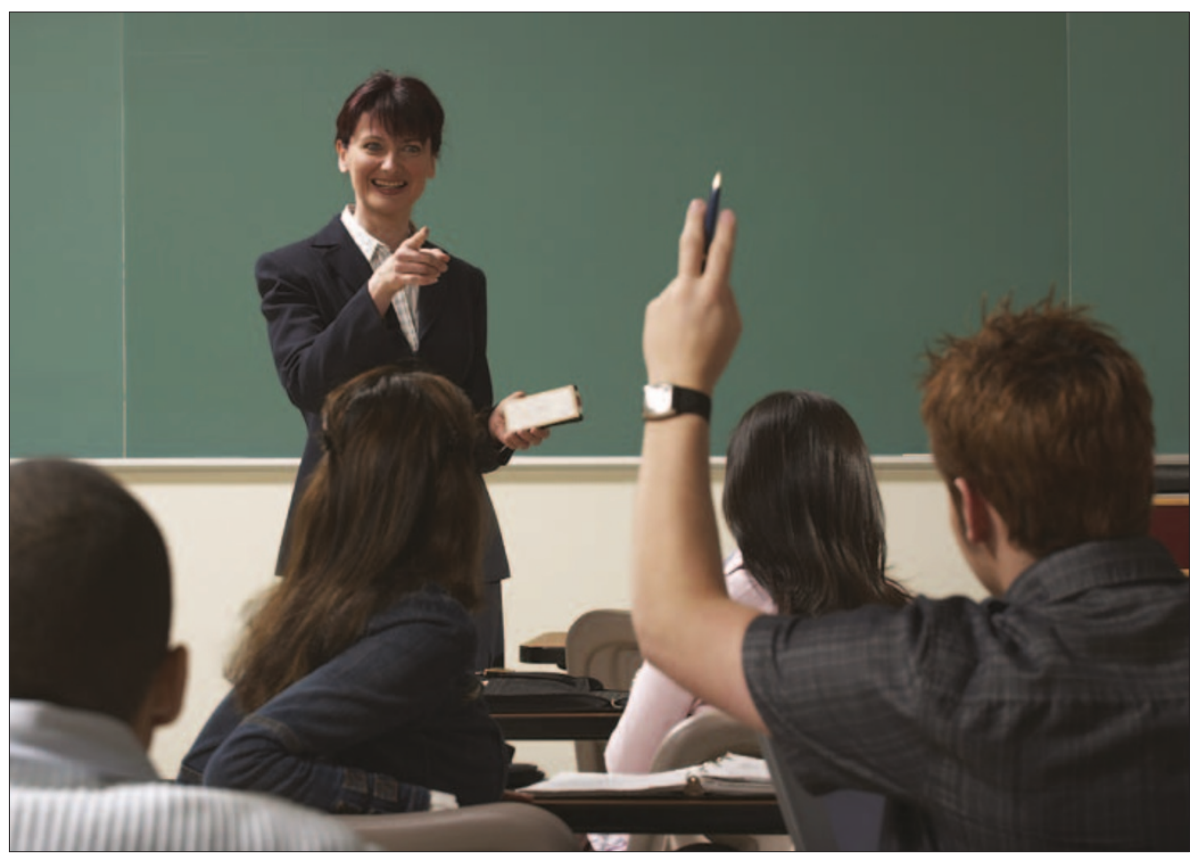

The survey looked at the career plans of prospective dental students

The dental profession would be severely affected if both men and women took time out of their careers in the future, according to a survey of dental school applicants' career intentions and the balance with family life, to be published in the next issue of the $B D J$.

The study by L.Carson from the University of Abertay, Dundee, G. Hoad Reddick of the University of Manchester, FMJ Stewart and JR Drummond both of Dundee Dental School, investigated the career plans of prospective dental students and how they foresaw their work life balance.

As well as a workforce shortage, it claimed that the problems of access to NHS dental services would be exacerbated if fewer dentists choose to provide NHS care.
The study found that 95\% of respondents felt that a postgraduate qualification would assist their career prospects, and over 91\% considered childcare should be shared equally between both parents.

Over half the females surveyed said they would take time out of their careers when their children were of pre-school age compared with $34 \%$ of males and only $3 \%$ of those intending to enter general dental practice said they would work exclusively in the NHS.

The research also revealed that if both men and women were going to take career breaks in the future, this would exacerbate the problems of shortages in the dental workforce through women returning to work on a part time basis after having children and applicants recognising early on they would be unlikely to work exclusively in the NHS. One of the authors of the study, FMJ Stewart commented, "The findings emphasise the urgent need to address issues regarding workforce planning in the profession. Unless steps are taken, the provision of NHS dental services in the UK could be jeopardised in the future."

Lastly the study said that given the large proportion of respondents who felt that a postgraduate qualification would help their career, the implications of this would have a profound effect on the present capacity for postgraduate education. Alternatives to the traditional study route within the hospital setting needed to be developed to create pathways for GDPs and dentists in the CDS to work towards further qualifications.

See the next issue of the $B D J$ for full details.

\section{Call for action on cleft palate}

A global research network is needed if scientists are to understand and prevent cleft palate, say specialists at the first World Health Organisation Collaborating Centre set up to develop such a structure.

Professor Bill Shaw, of The University of Manchester, says the complexity of craniofacial anomalies, like cleft lip and palate means no one country or institution has the necessary expertise and resources to find all the answers to these conditions.

The university's School of Dentistry was designated a WHO Collaborating Centre for Research on the Treatment of Craniofacial Congenital Anomalies in recognition of the research carried out there into craniofacial disorders. Although substantial progress has been made into the causes and treatment of craniofacial anomalies over the last few years, Professor Shaw says there is still a long way to go before they are fully understood.

"A child is born with a cleft somewhere in the world every two minutes and it has become clear just how complex these conditions are," he said.

He added that although knowledge on the area had improved, there was still uncertainty about the best form of treatment and said a global, multi-centre approach was required.

The centre's ten-strong team is involved in a number of international collaborations. It looks after about 80 babies born with cleft palate in the Northwest each year and also organises international clinical trials.

\section{New Health Minister appointed}

Patricia Hewitt was appointed Secretary of State for Health earlier this month in a cabinet reshuffle.

She was formerly a Minister at the Department of Trade and Industry, Economic Secretary at the Treasury and Secretary of State at the DTI. She has been a Member of Parliament since 1997.

Ms Hewitt was educated at the Canberra Girls' Grammar School and Newnham College, Cambridge University.

In her previous roles she was Press and Broadcasting Officer and Policy Coordinator to the then Leader of the Opposition, the Rt. Hon. Neil Kinnock, Deputy Director of the Institute for Public Policy Research and Director of Research for Andersen Consulting. 


\section{Controlling oral cancer}

Fifty-seven countries have agreed a range of approaches to control oral cancer worldwide. The countries have all committed to the Crete Declaration, a statement on approaches for effective control of oral cancer at a global level.

The participants of the 10th International Congress on Oral Cancer which took place in April in Crete, Greece, welcomed the initiative to analyse the evidence on oral cancer and the implications for prevention and public health programmes.

They also emphasised that oral health is an integral part of general health and wellbeing and expressed concern about the neglected burden of oral cancer which particularly affects developing countries with low availability of prevention programmes and oral health services.
In the declaration, the participants affirmed their commitment to oral health and general health as a basic human right.

They resolved to support the work carried out by national and international health authorities, research institutions, non-governmental organisations and civil society for the effective control of oral cancer.

They also looked at areas of work that should be strengthened. These included the provision of systematic epidemiological information on prevalences of oral cancer and cancer risks in countries, particularly in the developing world and promotion of research into understanding biological, behavioural and psychosocial factors in oral cancer, emphasising the inter-relationship between oral health and general health.

\section{New discovery may eliminate tooth sensitivity}

Sensitive teeth could be a thing of the past thanks to a new discovery at Leeds Dental Institute. Professor Jack Toumba and Dr Gayatri Kotru have discovered that fluoride beads inserted into brackets in the mouth appear to eliminate tooth sensitivity entirely. The researchers made this chance finding in 1999 when a volunteer testing the effect of the fluoride beads on tooth decay said her tooth sensitivity had disappeared.

They followed this with a small trial of sufferers and found that in every case the sensitivity disappeared. "The beads have a two in one effect - although we were focusing on decay, in doing so we discovered that it had a positive effect on tooth sensitivity," said Dr Kotru. "We were inspired to take this a step further."

They are now embarking on a study of 100 volunteers with tooth sensitivity, giving half a placebo and half the fluoride beads, which are inserted into brackets on the upper first molar on either side of the mouth.

The fluoride, they believe, causes a precipitation which blocks up the tiny fluid-filled tubules in the dentine which cause sensitivity when they become exposed.

Professor Toumba hopes the results will improve the lives of tooth sensitivity sufferers. "Desensitising toothpastes have only a temporary effect. Our bead is

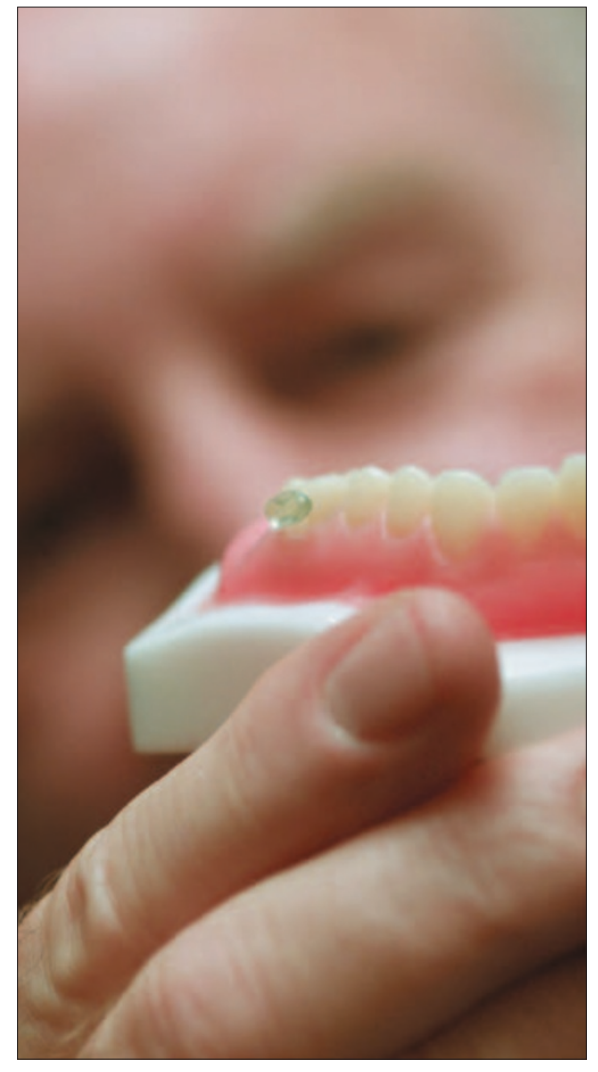

The fluoride beads appear to eliminate tooth sensitivity

replaced easily and painlessly every two years, giving constant freedom from tooth sensitivity," he said. 